\title{
TELAAH RESEPSI PERNIKAHAN ADAT JAWA DALAM PERSPEKTIF HUKUM ISLAM
}

\author{
${ }^{1}$ Romli, ${ }^{2}$ Eka Sakti Habibullah \\ ${ }^{1,2}$ Dosen Tetap Prodi Al Ahwal Asy Syakhshiyah STAI Al Hidayah Bogor \\ eka635962@gmail.com
}

Received: 04-10-2018, Accepted: 15-10-2018, Published: 26-10-2018

\begin{abstract}
Reception at weddings is something that is entrenched in society, especially for Muslims. Islam recommends that anyone who marries, then invite relatives, neighbors and people he knows. This is done in order to ward off slander, for people who are known. The Islamic community in Java to do a wedding reception is very difficult, a lot of rituals to do. However, the reception is also varied depending on the ability of the two parents of the bride. The Javanese community is classified into four categories; DKI, JABAR, JATENG, and JATIM. Research is directed at Central Java, remembering more is displayed; both the Ministry of Education and Culture's print, electronic and documentation media. So that researchers are easier to get data. Researchers search data through some documentation in the media. Thus the researcher is easy to do data collection. Data obtained from documentation and information taken from Youtube documentation and other media. Efforts to search for data are maximized in each region located in Central Java. Central Java has traditional wedding reception standards such as; Solo and Yogyakarta. Data analysis used a descriptive approach, where researchers only provide an overview of wedding receptions in Central Java. In conducting research using qualitative research. As for drawing conclusions directed to the formulation of the problems that have been previously designed, so that will produce optimal conclusions.
\end{abstract}

Keywords: marriage reception, islamic law and javanese traditional.

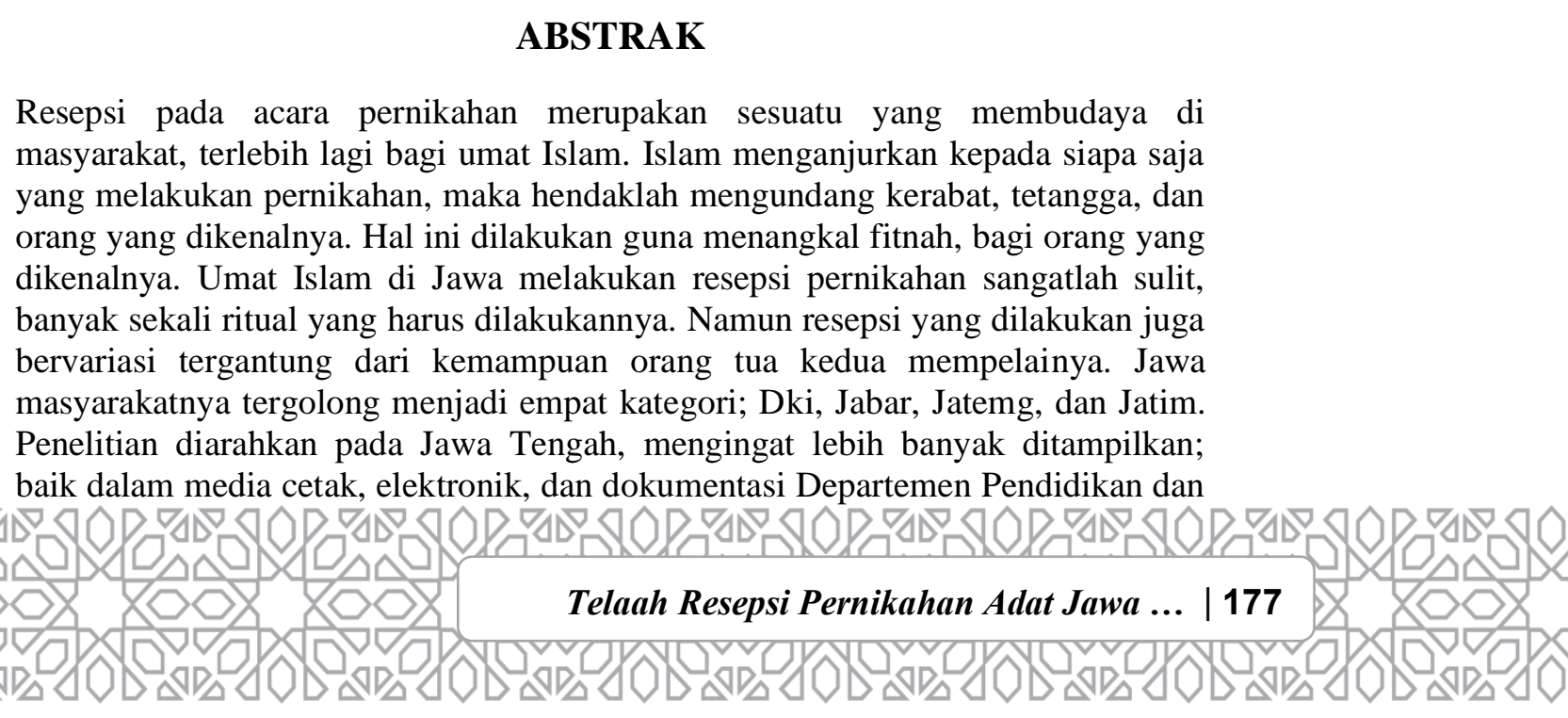


Kebudayaan. Sehingga peneliti lebih mudah untuk mendapatkan data.Peneliti melakukan pencarian data melalui beberapa dokumentasi yang ada di media. Dengan demikian peneliti mudah untuk melakukan pengumpulan data. Data didapat dari dokumentasi serta keterangan yang diambil dari dokumentasi Youtube dan media lain. Upaya untuk melakukan pencarian data dimaksimalkan pada setiap daerah yang terletak di Jawa Tengah. Jawa Tengah memiliki standar resepsi pernikahan adat seperti Solo dan Yogyakarta. Analisis data yang digunakan pendekatan deskriptif, dimana peneliti hanya memberikan gambaran tentang resepsi pernikahan yang terdapat di Jawa Tengah. Dalam melakukan penelitian menggunakan qualitative research. Adapun penarikan kesimpulannya diarahkan pada rumusan masalah yang telah didesain sebelumnya, sehingga akan menghasilkan kesimpulan yang optimal.

\section{PENDAHULUAN}

Resepsi pernikahan adalah bagian dari proses yang di sunnahkan Rasulullah S.A.W., sebagaimana sabda Beliau S.A.W.: "Laksanakanlah walimah walaupun hanya dengan menghidangkan seekor kambing." (H.R. Muslim). Resepsi merupakan bagian menghindari fitnah sehingga proses pernikahan secara informatif bertujuan agar diketahui banyak orang serta menghilangkan peluang sikap berburuk sangka. Para fuqaha berpendapat bahwa melaksanakan walimah hukumnya wajib berdasar hadits di atas. Terlepas fuqaha berselisih pendapat terkait yang bertanggung jawab atas pembiayaannya, apakah di bebankan kepada mempelai pria atau keluarga mempelai pengantin wanita. Islam yang menjadi pernikahan sebagai bagian tuntunan yang disyariatkan pun memberi rambu-rambu tentang bagaimana proses pra nikah dan pasca nikah termasuk resepsi pernikahan (walimah) dengan tetap menjaga norma norma syariat sehingga tidak justru menodai kesucian dan keberkahan pernikahan itu sendiri.

Indonesia memiliki kekayaan budaya dan adat yang beragam. Di antara budaya dan adat tersebut menyerap dalam beberapa syiar Islam termasuk dalam masalah pernikahan dalam beberapa prosesinya, terutama resepsi pernikahan dalam adat dan budaya jawa. Tentu adat atau budaya apapun ketika tidak bertentangan dengan ketentuan Islam maka wajib di jaga kelestariannya, namun bertentangan maka wajib ditinggalkan. Dalam teori masyarakat minang dikenal 
dengan istilah "Adat basandi syara', syara' basandi kitabullah.",

Kaitan hubungan hukum adat dan hukum Islam beberapa teori yang diangkat oleh para ilmuwan. Teori receptio in complexu ${ }^{2}$ bahwa masyarakat di Indonesia telah masuk Islam dan menerima hukum Islam sebagai bagian dari adat budaya mereka, terlepas masih ada penyimpangan. Teori receptie ${ }^{3}$ artinya hukum yang berlaku pada masyarakat adat pada dasarnya hukum adat. Kemudian Hazairin memunculkan teori receptie exit ${ }^{4}$ bahwa penerimaan hukum Islam oleh hukum adat secara selektif harus keluar (exit) dari hukum positif di Indonesia. Setelah itu muncul teori receptio a contrario ${ }^{5}$ artinya hukum Islam menerima hukum adat selama tidak bertentangan dengan nilai-nilai Islam, teori ini sebagai

${ }^{1}$ Artinya adat itu berdasar syariat Islam dan syariat berdasarkan kitabullah (al-Quran).

2 Teori ini menyatakan bahwa hukum yang berlaku bagi umat Islam adalah hukum Islam secara menyeluruh dan mutlak walaupun masih terdapat beberapa penyimpangan. Teori ini dikaji oleh Van Deb Berg (1845-1927). Lihat: Juhaya S. Praja. (2011). Teori Hukum dan Aplikasinya, Bandung: Pustaka Setia, h.di.

${ }^{3}$ Dikembangkan oleh Snock Hurgounjte (1857-1936) yaitu penerimaan hukum Islam dengan syarat tidak bertentangan dengan adat.

4 Hazairin. (1985). Tujuh Serangkai Tentang Hukum. Jakarta: Bina Aksara. hlm. 54.

Sajuti Thalib. (1985). Receptio A Contrario. Jakarta: Bina Aksara. hlm. 58. antitesa dari teori recetie. Abdullah Syah dalam penelitiannya tentang hukum Islam dan hukum adat di Langkat Sumatra Utara menyimpulkan antara hukum Islam dan hukum adat saling mengisi dan melengkapi keduanya bisa sejalan. $^{6}$ Andi Rasdiyansa meneliti integrasi adat Bugis dengan Islam pada sistem "pangngaderreng," yaitu petuah petuah raja dan orang bijak di Bone pada abad ke 16-17, disimpulkan bahwa petuah petuah tersebut mengadopsi hukum Islam dimana pengadopsian dilakukan dengan penyerapan nilai nilai syariat kedalam adat istiadat dan sistem hukum Bugis Bone. ${ }^{7}$

\section{PEMBAHASAN}

\section{A. Pernikahan Menurut Hukum Islam}

Pernikahan merupakan ibadah yang dengannya wanita muslimah telah menyempurnakan setengah dari agamanya serta akan menemui Allah dalam keadaan suci dan bersih. Hal ini sebagaimana diriwayatkan dari Anas رضي الله عنه,

${ }^{6}$ Abdullah Syah. (1984). Integrasi antara Hukum Islam dan Hukum Adat dalam Kewarisan Suku Melayu di Kecamatan Tanjung Pura Langkat, Disertasi Hukum Islam, UIN Syarif Hidayatullah, Jakarta.

7 Andi Rasdiyansa. (1995). Integrasi Sistem Pangngaderreng (adat) Dengan Sistem Syariat Islam Sebagai Pandanga Hidup Orang Bugis, Disertasi Hukum Islam, Yogyakarta, UIN Sunan Kalijaga. 
bahwa Rasulullah telah bersabda:

$$
\begin{aligned}
& \text { من رزقه الله امرأة صا لحة فقد أعا نه } \\
& \text { على شطر دينه فليتق الله في الشطرالبا } \\
& \text { في } \\
& \text { "Barangsiapa diberi oleh } \\
& \text { Allah seorang istri yang } \\
& \text { sholehah, maka dia telah } \\
& \text { membantunya untuk } \\
& \text {,menyempurnakan setengah } \\
& \text { dari agamanya. Untuk itu, } \\
& \text { hendaklah ia bertakwa kepada } \\
& \text { Allah pada setengah lainnya." } \\
& \text { (H.R. Ath-Thabrani dan Al- } \\
& \text { Hakim })^{8}
\end{aligned}
$$

Allah menjanjikan

pertolongan bagi seseorang yang menikah, sebagaimana dalam firmanNya:

$$
\begin{aligned}
& \text { وَأَنْكِحُوا الََََْْامَى مِنْكُمْ وَالصَّالِحِينَ مِنْ } \\
& \text { عِبَادِكُمْ وَإِمَائكِكُمْ إِنْ يَكُونُوا فُقَرَاءَ يُفْنِهِمُ } \\
& \text { اللَّهُ مِنْ فَضْلِلِهِ وَاللَّهُ وَاسِِِع عَلِيمٌ }
\end{aligned}
$$

"Dan nikahkanlah orangorang yang masih membujang di antara kamu, dan juga orang-orang yang layak (menikah) dari hamba-hamba sahayamu yang laki-laki dan perempuan. Jika mereka miskin, Allah akan memberi kemampuan kepada mereka dengan karunia-Nya. Dan Allah Maha luas (pemberianNya), Maha Mengetahui." (QS. An-Nur [24]: 32) ${ }^{9}$

Menurut Zakiyat Darajat ada lima tujuan dalam pernikahan, yaitu:

a. Mendapatkan dan melangsungkan keturunan

b. Memenuhi hajat manusia menyalurkan syahwatnya dan menumpahkan kasih sayangnya

c. Memenuhi panggilan agama, memelihara diri dari kejahatan dan kerusakan

d. Menumbuhkan kesungguhan untuk bertangggung jawab menerima hak serta kewajiban juga bersungguh-
${ }^{8}$ Kamil Muhammad Uwaidah (2013). Fiqih Wanita Edisi Lengkap, Jakarta: AlKautsar. hlm. 339.
${ }^{9}$ Yazid bin Abdul Qadir Jawas. (2011). Panduan Keluarga Sakinah, Jakarta: Pustaka Imam Asy-Syafi' i. .hlm 20 
sungguh untuk memperoleh harta kekayaan yang halal. ${ }^{10}$

Terhadap adat yang berkaitan ada dalam sebelum pernikahan, akad nikah dan setelah akad pernikahan selama tidak melanggar hukum islam selaku tokoh masyarakat tidak mempermaslahkan bahkan dalam kaidah fiqiyah.

\section{B. Pernikahan \\ Menurut Masyarakat Adat \\ Pernikahan menurut masyarakat} adalah suatu ikatan suci/sakral antara laki-laki dan perempuan yang sudah dewasa mencapai umur 17 tahun, sudah mampu mandiri dalam hal mengurus badan sendiri dan pasangan hidupnya, mampu bertanggung jawab membangun rumah tangga dengan dasar saling mencintai satu sama lain. Maka harus menjalin hubungan yang sah dengan akad ijab kabul.

Pernikahan adat jawa adalah suatu rangkaian upacara yang dilakukan sepasang kekasih untuk menghalalkan semua perbuatan yang berhubungan dengan kehidupan suami-istri guna membentuk suatu keluarga dan

10 Tihami dan Sohari Sahrani. Fiqih Munakahat Kajian Fikih Nikah Lengkap. hlm. 10. meneruskan garis keturunan. Guna melakukan prosesi pernikahan, orang Jawa selalu mencari hari baik, maka perlu dimintakan pertimbangan dari ahli penghitungan hari baik berdasarkan patokan Primbon Jawa. Setelah ditemukan hari baik, maka sebulan sebelum akad nikah, secara fisik calon pengantin perempuan disiapkan untuk menjalani hidup pernikahan, dengan cara diurut perutnya dan diberi jamu oleh ahlinya. pengurutan itu dilakukan diperut untuk menempatkan rahim dalam posisi yang tepat agar dalam persetubuhan pertama memperoleh keturunan, dan minum jamu Jawa agar tubuh ideal dan singset. ${ }^{11}$

Peran pernikahan dalam hukum pernikahan adat di berbagai daerah Indonesia dalam penyelenggaraannya tidaklah sama terdapat perbedaan adat istiadat atau pengaruh agama dalam pelaksanan adat pernikahan.pelaksanaannya juga berbeda, ada yang sederhana dan ada yang besar-besaran tergantung kondisi keuangan dan status sosial mereka. ${ }^{12}$

11 Wurtamto. Pegawai Pencatat Nikah. Desa Terlangu

12 Hilman Hardikusuma. (1990). Pengantar Ilmu Hukum Adat Indonesia. Mandar 
Menurut masyarakat desa Terlangu, sebuah pernikahan itu dua keluarga akan menjadi satu keluarga besar, bisa jadi dua keluarga tersebut berasal dari suku budaya yang sama ataupun berbeda. Biasanya, jika kedua keluarga berasal dari suku budaya yang sama, maka adat istiadat akan sangat diperkuat dan dilaksanakan berbagai upacara atau ritual. Diantaranya Lamaran, mencari hari yang baik sesuai primbon dan menetukan hari pernikahan, daftar ke Kantor Urusan Agama, pasang tarub atau penggung hiasan pengantin, menyuruh tetangga bergotong royong dalam pelaksanaan pernikahan dalam hal masak memasak biasanya disebut sinoman, mencari rias pengantin, sarahan, ijab kabul, adat sembah sungkem, iring-iring pengantin, rayahan duit, adat langkah pengantin, adat anak pertama, adat anak terakhir, menyediakan sesajen di atas damar panggung. ${ }^{13}$

Masyarakat hukum adat yang susunannya didasarkan atas pertalian keturunan menurut suatu garis altenerend adalah masyarakat hukum

Maju, Bandung: Citra Aditya Bakti. hlm. 97109.

${ }^{13}$ Sesepuh. Masyarakat Desa Terlangu adat yang para nggotanya menarik garis keturunan berganti-ganti secara bergiliran melalui garis ayah maupun melaui garis Ibu sesuai dengan bentuk perkawinan yang dialami oleh orang tua, yaitu bergiliran kawin jujur, kawin semendo maupun kawin semendo rajorajo (Rejang). ${ }^{14}$

Apabila hukum adat tidak dipelajari, sebagai suatu ilmu pengetahuan, maka pada umumnya di kalangan masyarakat daerah dalam pembicaraan sehari-hari atau dalam kerapatan-kerapatan adat orang tidak membedakan antara hukum adat dengan adat. jadi dengan mengatakan adat, berarti pula meliputi hukum adat, baik adat tanpa sanksi maupun adat yang mempunyai sanksi. akan tetapi apabila hukum adat ini ingin dipelajari sebagai suatu studi disiplin ilmu pengetahuan tersendiri, maka haruslah dibedakan antara keduanya, sebab agar jelas kemudian bidang telaahan yang akan diakukan terhadap ilmu pengetahuan ini

${ }^{14}$ Bushar Muhammad. (1997). Asas-asas Hukum Adat suatu pengantar. Jakarta: Pradnya Paramita. hlm .28. 
eksistensinya sebagai salah satu bidang disiplin ilmu pengetahuan. ${ }^{15}$

\section{Menurut Soerjono Soekanto} hukum adat pada hakikatnya merupakan hukum kebiasaan, artinya kebiasaankebiasaan yang mempunyai akibat hukum (sein-sollen). berdeda dengan kebiasaan belaka, kebiasaan yang merupakan hukum adat adalah perbuatan-perbuatan yang diulang-ulang dalam bentuk yang sama yang menuju pada "rechtsvardigeordening der samenlebing",16

Hukum pernikahan adat ini adalah aturan-aturan hukum adat yang mengatur tentang bentuk-bentuk pernikahan, cara-cara pelamaran, upacara penikahan dan putusnya pernikahan di Indonesia. Aturan-aturan ini di berbagai daerah Indonesia memiliki perbedaan satu sama lain dikarenakan sifat kemasyarakatan, adat istiadat, agama, dan kepercayaan yang berdeda-beda. Di samping itu, hukum adat mengalami pula beberapa

${ }^{15}$ Dewi Wulansari. (2010). Hukum Adat Indonesia Suatu Pengantar. Bandung: PT. Refika Aditama. hlm. 6-7.

${ }^{16}$ Soerjono Soekanto. (1976). Beberapa Permasalahan Hukum dalam Kerangka Pembangunan di Indonesia. Yayasan Penerbit Universitas Indonesia, Jakarta, hlm. 11. perubahan atau pergeseran-pergeseran nilai dikarenakan adanya faktor perubahan zaman, terjadinya perkawinan antara suku, adat istiadat, dan agama serta kepercayaan yang berlainan. $^{17}$

\section{Resepsi Pernikahan}

Resepsi pernikahan adalah mengundang orang terdekat, di antaranya:

1. Termasuk etika memenuhi undangan dan menghadirinya ialah janganlah seseorang menghadirinya bertujuan hanya untuk memuaskan nafsu makan perutnya, melainkan berniatlah untuk mengikuti perintah syari'at, menghormati dan menghindarkan tuduhan orang lain yang bukan-bukan terhadap dirinya dan saudara yang mengundangnya itulah bila tidak mengadirinya.

$$
\begin{aligned}
& \text { وَعَنْ إِبْنِ عُمَرَ - رَضِيَ الَلَُّ عَنْهُمَا- قَالَ : }
\end{aligned}
$$

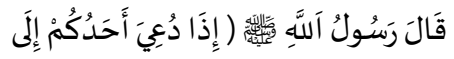

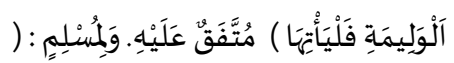

${ }^{17}$ Dewi Wulansari. (2010). Hukum Adat Indonesia. Bandung: PT. Refika Aditama. hlm. 47. 


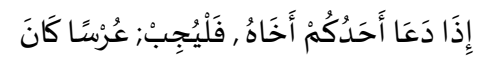

$$
\text { أَوْ نَحْوَهُ ( }
$$

رَضِيَ آَلَّهُ Dari Ibnu Umar

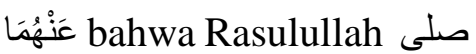
bersabda: "apabila seorang diantara kamu diundang ke walimah, hendaknya ia menghadirinya".

(H.R.

Al-Bukhori dan Muslim).

Menurut riwayat Muslim: "Apabila salah seorang di antara kamu mengundang saudaranya, hendaknya ia memenuhi undangan tersebut baik itu walimah pengangantin atau semisalnya. ${ }^{18}$

2. Hendaknya berdoa untuk kebaikan shahibul walimah yang mengundangnya usai menyantap hidangannya. Telah diriwayatkan dari 'Abdullah ibnu Busr bahwa ayahnya membuat jamuan makan untuk Nabi lalu Ayahnya mengundangnya nabi صلى الله عليه وسلم berdoa : Ya Allah, berikanlah ampunan bagi mereka, rahmatilah mereka dan berkatilah mereka dalam rezeki yang telah engkau berikan kepada mereka. (HR. Muslim dan Tirmidzi)

3. Tidak boleh menghadiri walimah, jika di dalamnya terdapat kedurhakaan, terkecuali untuk tujuan memprotesnya dan berupaya untuk menghentikannya, tetapi dengan syarat jika memang upayanya itu akan membuahkan hasil, tetapi jika tidak akan membuahkan hasil apapun, maka harus menarik diri dari menghadirinya. ${ }^{19}$

$$
\begin{aligned}
& \text { وَعَنْ أَبْي هُرَيْرَةَ هُنَّهُ قَالَ : قَالَ رَسُولُ }
\end{aligned}
$$

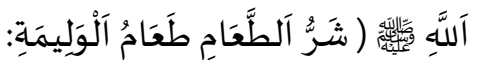

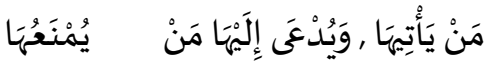

$$
\begin{aligned}
& \text { يَابْتَاهَا ,وَمَنْ لَمْ يُجِبِ اَلََّّعْوَةَ فَقَدْ }
\end{aligned}
$$$$
\text { عَصَى آلََّهَ وَرَسُولَهُهُ أَخْرَجَهُ مُسنْلِمُ }
$$

18 Ibnu Hajar Atsqalani. (2009). Terjemah Hadits Bulughul Maram dengan Transliterasi Arab-Latin. No. 1069. Bandung: CV. Gema Risalah Press. hlm. 437.
${ }^{19}$ Thariq Ismail Kahiya. (2005). Menata Kalbu Membina Keluraga Bahagia. Bandung: Alif Media. hlm. 125-126. 
رضي الله Dari Abu hurairah صلى اله bersbda : "sejahatjahatnya makanan ialah makanan walimah, ia ditolak orang yang datang kepadanya dan mengundang orang yang tidak diundang. Maka barangsiapa tidak memenuhi undangan tersebut ia telah durhaka kepada Allah dan RasulNya”. HR. Muslim. ${ }^{20}$

\section{Tradisi Adat Jawa Menjelang}

\section{Upacara Pernikahan}

\section{Nontoni}

Pada dasarnya nontoni adalah suatu upaya dari pihak calon pengantin lakilaki untuk mengenal calon pengantin perempuan. Pada zaman dahulu, nontoni ini selalu dilaksanakan dan terkesan resmi. Pihak calon pengantin laki-laki bersama orang tua atau kerabat dekat datang ke rumah gadis yang

20 Ibnu Hajar Atsqalani. (2009). Terjemah Hadits Bulughul Maram dengan Transliterasi Arab-Latin. No. 1070. Bandung: CV. Gema Risalah Press. hlm. 437. ditaksirnya (bisa disebut calon pengantin perempuan). Tujuan nontoni adalah untuk lebih mengenal orang yang akan dijadikan istri. Pada zaman dahulu, nontoni selalu dilaksanakan karena pergaulan antara muda-mudi yang berbeda dengan zaman modern seperti zaman sekarang ini. Laki-laki dan perempuan muda tidak bisa bebas dalam bergaul seperti sekarang sehingga untuk lebih mengenal calon istri, seoang pemuda mesti melakukan satu tahap yang disebut nontoni. Pada zaman sekarang, acara nontoni sudah jarang dilaksanakan. Antara calon pengantin lakilaki dan perempuan sudah saling mengenal melalui pergaulan sehari-hari. Kebanyakan, pada zaman sekarang pihak calon pengantin laki-laki perlu melakukan nontoni. Pihak calon pengantin laki-laki kalau sudah mantap atas 
gadis pilihannya, langsung melamar.

2. Tangeran (Peningsinten) Apabila jeda antara lamaran dengan hari pernikahan masih lama, biasanya diadakan acara tengaran (peningsinten). Ada juga yang menyebutnya tukar cincin, yang dalam istiah populer adalah pertunangan. Pertunangan ini bertujuan untuk pihak tidak terpikat pada orang lain. Selain itu, pihak lain diluar sejoli yang telah bertunangan tersebut juga secara etika tidak akan berusaha mendekati salah satu dari pasangan yang telah bertunangan tersebut.

3. Nglamar

Nglamar atau melamar dilakukan oleh utusan dari pihak calon pengantin lakilaki. Jika lamaran diterima maka dilakukan peneguh pembicaraan yang disaksikan pihak ketiga ini bisa ketua RT (rukun tetangga), tokoh masyarakat, atau kerabat dekat dari pihak laki-laki dan perempuan. Acara nglamar ini bisa dibuat besar mewah, tetapi juga bisa dilakukan secara sederhana, tergantung kesepakatan berdua belah pihak. Jika dibuat mewah maka pihak laki-laki mempersiapkan ubarampe untuk melamar yang jumlahnya tergantung kemampuan. Acara nglamar yang mewah biasanya sekaligus melaksanakan acara pertunangan (tukar cincin).

4. Gethak dina

Gethak dina adalah penentuan hari ijab kabul dan resepsi pernikahan. Dalam masyarakat Jawa, gethak dina ditentukan oleh sesepuh atau orang yang ahli dan mengetahui tentang penanggalan Jawa. Hari yang dipilih adalah hari baik sesuai dengan perhitungan penanggalan Jawa yang disepakali oleh kedua belah pihak. Meskipun pihak perempuanlah yang berhak 
menentukan hari untuk ijab kabul dan resepsi, tetapi pihak laki-laki juga berhak mengetahui dan memberi masukan untuk hari istimewa tersebut. Jadi perhitungan penanggalan Jawa tersebut adalah hari baik bagi pihak calon pengantin laki-laki. $^{21}$

\section{E. Sistem Pernikahan}

Perlu diketahuai ada sistem pernikahan adat, di antaranya:

\section{Sistem endogami}

Orang hanya diperbolehkan kawin dengan orang dari suku keluarganya sendiri.

\section{Sistem exogami}

Orang diharuskan kawin dengan orang di luar suku keluarganya

\section{Sistem eleutherogami.}

Sistem ini tidak mengenal larangan seperti endogami dan exogami. Larangan yang terdapat dalam sistem ini adalah bertalian dengan ikatan

21 Gesta Bayuandhy. (2015). TradisiTradisi Adiluhung Para Leluhur Jawa. Yogyakarta: Dipta. hlm. 60-62. kekeluargaan, yaitu karena:

a) Nasab (turunan yang dekat), seperti kawin dengan ibu, nenek, anak kandung, cucu, juga dengan saudara kandung, saudaranya bapak atau saudaranya ibu.

b) Musyaharah (per iparan), seperti kawin dengan ibu tiri, menantu, mertua, atau anak tiri.

\section{F. Telaah Resepsi Pernikahan Adat Jawa}

1. Berdasarkan hasil penelusuran secara teori atau hukum Islam, yang penulis paparkan di atas:

a) Selama syarat dan rukun nikah terpenuhi, maka tidak bertentangan dengan hukum Islam

b) Dalam melakukan tradisi rangkaian upacara harus senantiasa berpedoman pada sisi syari'ah

c) Resepsi pernikahan hendaknya dilakukan 
secara sederhana dan

tidak bermegah-megah.

2. Berdasarkan teori dan keterangan perihal pernikahan terkait masyarakat dan adat Jawa, di antaranya:

a) Dalam perencanaan resepsi pernikahan, adat Jawa telah mengedepankan hal-hal; nontoni, tangeran, ngalamar, dan gethak dina tidak bertentangan dengan syari'ah.

b) Pada prosesinya ada upacara lainnya seperti; mandi kembang, injak telur, dsn lainnya (harus berhati-hati), prosesproses tersebut sangat kental dengan mitosmitos khurafat bahkan merupakan sikap mengada-ngada dalam masalah beragama bahkan dikhawatirkan terjadi tindakan kemusyrikan yang merupakan dosa besar yang harus diwaspadai setiap muslim.

c) Pada menyambutan tamu kepada mempelai, disarankan memisahkan antara mempelai pria dan wanita.

3. Resepsi pernikahan

a) Resepsi pernikahan merupakan keharusan dan tidak boleh menikah sembunyi-sembunyi, hal ini untuk menghindari dari yang tidak diinginkan.

b) Kehadiran keluarga, teman, dan tetangga sangat diharapkan kehadirannya atau bila berhalangan hadir, maka setidaknya telah mengetahuinya.

c) Resepsi pernikahan juga termasuk memberikan informasi secara langsung kepada masyarakat, bahwa telah terjadi sebuah pernikahan pada saat itu.

d) Disarankan sebaiknya mengadakan resepsi 
pernikahan tidak terlalu jauh dari tempat mempelai dan menghindari resepsi pernikahan secara bermewah-mewahan.

\section{KESIMPULAN}

Hukum Islam dan hukum adat saling mengisi dan saling melengkapi. Sehingga setiap hukum adat dan budaya yang tidak bertentangan di kuatkan oleh syariat bahkan di beberapa wilayah Indonesia hukum Islam terserap ke dalam hukum adat. Tidak terkecuali dalam pernikahan adat Jawa dimana aturan-aturan hukum adat yang mengatur tentang bentuk-bentuk pernikahan, cara-cara pelamaran, upacara penikahan dan putusnya pernikahan di Indonesia. Aturan-aturan ini di berbagai daerah Indonesia memiliki perbedaan satu sama lain dikarenakan sifat kemasyarakatan, adat istiadat, agama, dan kepercayaan yang berdeda-beda.

Seorang muslim tentunya tunduk terhadap hukum agama yang diyakininya. Oleh karena itu maka seharusnya ia menjadikan hukum Islam sebagai analisis dan standar untuk menilai hukum adat tidak justru hukum adat mengkoreksi hukum Islam. Dalam pernikahan adat Jawa masih ada beberapa prosesi baik pranikah atau pasca nikah yang bertentangan dengan nilai-nilai syariat sehingga harus dihilangkan.

\section{DAFTAR PUSTAKA}

Al-Atsqalani, I. H. (2009). Terjemah Hadits Bulughul Maram dengan Transliterasi Arab-Latin. No. 1069. Bandung: CV. Gema Risalah Press.

Dewi, W. (2010). Hukum Adat Indonesia. Bandung: PT. Refika Aditama.

Gesta, B. (2015). Tradisi-Tradisi Adiluhung Para Leluhur Jawa. Yogyakarta: Dipta.

Hazairin. (1985). Tujuh Serangkai Tentang Hukum. Jakarta: CV Bima Aksara.

Hilman, H. (1990). Pengantar Ilmu Hukum Adat Indonesia. Mandar Maju, Bandung: Citra Aditya Bakti.

Ismail, K. T. (2005). Menata Kalbu Membina Keluraga Bahagia. Bandung: Alif Media.

Jawas, Y. b. (2011). Panduan Keluarga Sakinah. Jakarta: Pustaka Imam Sy-Syafi'i. 
Muhammad, B. (1997). Asas-asas Hukum Adat suatu pengantar. Jakarta: Pradnya Paramita.

Muhammad, U. K. (2013). Fiqih Wanita Edisi Lengkap. Jakarta: Al-kautsar.

Praja, J. S. (2011). Teori Hukum Dan Aplikasinya. Bandung: Pustaka Setia.

Soerjono, S. (1976). Beberapa Permasalahan Hukum dalam Kerangka Pembangunan di Indonesia. Jakarta: Yayasan Penerbit Universitas Indonesia.

Thalib, S. (1985). Receptio A Contrario. Jakarta: cet IV,CV Bima Aksara.

Wulansari, D. (2010). Hukum Adat Indonesia Suatu Pengantar. Bandung: PT. Refika Aditama.

Abdullah Syah, Integrasi antara Hukum Islam Dan Hukum Adat Dalam
Kewarisan Suku Melayu di Kecamatan Tanjung Pura Langkat, Disertasi Hukum Islam, 1984, UIN Syarif Hidayatullah, jakarta.

Andi Rasdiyansa, Integrasi

Sistem Pangngaderreng (adat) Dengan

Sistem Syariat Islam Sebagai Pandanga Hidup Orang Bugis, Disertasi Hukum Islam, Yogyakarta, UIN Sunan Kalijaga, 1995.

Sesepuh. Masyarakat Desa Terlangu.

Tihami dan Sohari Sahrani. Fiqih Munakahat Kajian Fikih Nikah Lengkap

Wurtamto. Pegawai Pencatat Nikah. Desa Terlangu. 